\title{
Role of Intraoperative Scrape Cytology in Diagnosis of Palpable Breast Lump
}

\author{
Shahe Systa Mosarrat ${ }^{1 *}$ \\ Md. Zillur Rahman ${ }^{1}$ \\ M Shahab Uddin Ahamad ${ }^{1}$ \\ Pradip Bhattacharjee ${ }^{1}$ \\ Sayeeda Nasreen ${ }^{1}$ \\ Ismail Hossain ${ }^{1}$ \\ Md. Didarul Alam² \\ 'Department of Pathology \\ Chittagong Medical College \\ Chittagong, Bangladesh \\ ${ }^{2}$ Department of Radiology \& Imaging \\ USTC, Chittagong, Bangladesh.
}

\begin{abstract}
Background: Diseases of the breast constitute a significant proportion of surgical cases and frequently, the need arises to distinguish benign from malignant lesions prior to definitive treatment. So far, Frozen Section (FS) is the standard technique with high level of validity. However, intraoperative scrape cytology can be adopted when special facilities of FS are not available. Methods: This study designed with the aim to evaluate the value of Intraoperative Scrape Cytology (IOSC) in providing rapid and accurate diagnosis for breast lump and to compare its diagnostic yield with that of paraffin sections. This cross sectional descriptive study was carried out in the Department of Pathology, Chittagong Medical College in collaboration with Department of Surgery of this institution from October 2013 to September 2014. The study conducted on 123 patients with breast lumps who underwent operative treatment. Scrapings were taken from each specimen before formalin fixation and stained by rapid Papanicolaou staining. In each case their accuracy was compared to histopathological diagnosis. Statistical analysis done employing $\chi^{2}$ test. Results: Out of 123 cases studied, 122 could be correctly differentiated into benign and malignant tumors with an accuracy rate of $99.19 \%$. Conclusion: Intraoperative Scrape Cytology (IOSC) is a simple, accurate, rapid and cost-effective diagnostic tool, not requiring specific instruments in contrast to frozen section, can be used peroperatively for both diagnosis and management of breast lump.
\end{abstract}

Key words: IOSC; Palpable breast lump; Intraoperative diagnosis.

\section{INTRODUCTION}

Lesions of the breast which are predominantly confined to the female have gained a great deal of global attention because of increasing mortality and morbidity caused by breast cancer ${ }^{1}$. In developing countries, breast cancer usually ranks second, after cervical cancer ${ }^{2}$. Increase incidence of breast cancer related to late marriage, birth of child in later age, shorter period of breast feeding and nulliparity or low parity ${ }^{3}$.

The palpable breast lump is a common diagnostic problem to the general practitioners and surgeons ${ }^{4}$. A breast lump is the most common symptom associated with breast cancer. 1 in 10 women with a breast lump will have breast cancer ${ }^{5}$. In the assessment of breast lesions, the most important role of diagnostic cytology is in making the binary decision between benign and malignant categories ${ }^{1}$. Fine Needle Aspiration Cytology (FNAC) of breast lump is an accepted and established method to determine the nature of the lump ${ }^{3}$. FNAC has its own limitations in terms of sensitivity and specificity. Many a times FNAC leads to a diagnosis that is 'suspicious, but not confirmatory' .

There are authors who advocate that mastectomy be performed solely based on cytology reports, whereas others advise Frozen Section (FS) confirmation. According to Silverman et al, by utilizing FNA biopsy with frozen section confirmation in a specific situation, a more accurate diagnosis can be offered with virtual elimination of false positive diagnosis and, thereby, unnecessary mastectomies ${ }^{7}$. 
Frozen section is routinely used by the surgical pathology laboratories for intraoperative diagnosis. Many studies have been done in the past to evaluate the role of cytology in intraoperative diagnosis of tumor. These studies have concluded that cytology has the advantage of being much less time consuming, easy to adopt, reliable and does not require special instruments. Hence, scrape cytology can be employed routinely in the intraoperative diagnosis of tumors. The use of either frozen section or intraoperative scrape cytological examination alone has an acceptable rate (93-97\%) of correct diagnosis with regard to interpretation of benign versus malignant ${ }^{8}$.

Scrape cytology avoids tissue artifacts produced during freezing sectioning done in frozen section, requires minimal tissue for diagnosis and saves the specimen for permanent sections and special studies. It has greater ability to detect micro metastasis, can be done inexpensively with materials available in most surgical laboratories, avoids contamination by infected tissues of the cryostat used in frozen section and provides clearer cellular details ${ }^{9}$.

Many studies have demonstrated that the diagnostic efficacy of intraoperative cytology is comparable to that of frozen section $^{10}$

Commonly used methods for obtaining and preparing cells for intraoperative cytological evaluation are imprint cytology, Fine Needle Aspiration Cytology (FNAC) and scrape smear preparation. ${ }^{[8]}$ Scrape cytology is a modification of imprint cytology and its diagnostic accuracy is better than imprint cytology. Scraping of the cut surface prior to smearing facilitates the harvesting of cells. Hence, scrape cytology can be preferred over imprint cytology as the former technique will yield much more material than the latter ${ }^{11}$. So this study has been undertaken to know the utility of scrape cytology in the intraoperative diagnosis of tumor to improve the diagnostic accuracy of palpable breast lumps.

\section{MATERIALS AND METHODS}

It was a cross-sectional descriptive study which was carried out in the Department of Pathology, Chittagong Medical College (CMC) Chittagong, Bangladesh in collaboration with Department of Surgery Chittagong Medical College Hospital (CMCH) from October 2013 to September 2014. Total 123 patients with palpable breast lump who has given written consent to participate in this study were the study subjects. All consecutive patients with palpable breast lumps diagnosed by preoperative FNAC and underwent elective surgeries of breast lump were included. Intraoperative scrape smear was taken peroperatively in the Department of Surgery, $\mathrm{CMCH}$. Institutional ethical clearance was obtained. Clinical history, questionnaire, thorough physical examination and relevant investigations were recorded in details in all cases.
Intraoperative scrape smears were taken. At first, the tumor was bisected to note the macroscopic features. Then the cut surface was wiped off the excess blood, if present, with the help of a filter paper. The most appropriate area thought to be representative of the lesion was chosen. The area was scraped with a sharp scalpel or the end of a glass slide. A semi fluid drop thus obtained was spread over a glass slide. On an average, four slides per case were prepared from different representative areas, immediately putted into 95\% ethyl alcohol for fixation and stained with rapid Papanicolaou (Pap) stain. The slides were examined immediately and reported as benign or malignant.

The specimens were then fixed in $10 \%$ formalin. Paraffin blocks of the sections were processed in the routine way and 5 micrometer thick sections were stained with Hematoxylin and Eosin (H \& E) stain. The stained sections were examined in the light microscope to get a definitive diagnosis of the lesions and its type.

The diagnosis obtained by intraoperative scrape cytology was compared with those of paraffin sections. Preoperative FNAC report also collected. The overall diagnostic accuracy of intraoperative scrape cytology for specific type of benign and malignant breast lesion was also found out.

All the patients included in this study were informed and explained about the nature of study. Informed written consent was taken from all the subjects after full explanation of the nature, purpose and potential risks of all the procedures to be taken out for the study.

The data analysis was done using the 'SPSS version-18' software. The association between intraoperative scrape cytology and histopathology was tested by Chi square test. Various indices such as sensitivity, specificity, false positive rate, false negative rate, positive predictive value, negative predictive value and accuracy were calculated.

\section{RESULTS}

The age range of 123 patients was 12 years to 65 years with a mean age 31.41 years $(\mathrm{SD} \pm 14.31)$. On the basis of age, patients were divided into six groups and it was seen that maximum number of patients $39(31.7 \%)$ were in age group 21-30 years followed by 20 years group $36(29.3 \%)$ (Table 1$)$.

Among 123 the cases, 89 (72.4\%) cases were married and 34 $(27.6 \%)$ cases were unmarried women. Among married women, $54(60.7 \%)$ had contraceptive history and 35 (39.3\%) had no contraceptive history. Maximum numbers 84 (68.3\%) were from average socioeconomic condition and incidence of breast lump was more common in housewives, which were 74 $(60.2 \%)$ (Table-2). The breast lumps of variable sizes were noted. Breast lump sizes were categorized into three groups according to American Joint Committee on Cancer (AJCC) staging system. Maximum numbers 93 (75.6\%) were 2-5 cm size, $21(17.1 \%)$ were $<2 \mathrm{~cm}$ size and $09(7.3 \%)$ were $>5 \mathrm{~cm}$ size. 
Intraoperative scrape smears were taken from all 123 cases. Out of them, $71(57.7 \%)$ cases were benign and $52(42.3 \%)$ were malignant. Among benign cases, 66 (53.7\%) were fibroadenoma(Figures-1,2), 03 (2.4\%) cases were fibrocystic disease, $01(0.8 \%)$ was benign phylloides tumour and $01(0.8 \%)$ was granulomatous inflammation (FNAC impression of this case was ductal carcinoma \& histopathological diagnosis was invasive lobular carcinoma). Among malignant cases, all were duct cell carcinoma (Figures- 3,4). Histopathological diagnosis showed $70(56.9 \%)$ benign lesions and 53 (43.1\%) malignant lesions.

Out of 71 benign IOSC impressions 70 proved to be benign histologically and 1 case was malignant. Out of 52 malignant IOSC impressions, all were proved to be malignant histologically. The association between IOSC impression and histopathological diagnosis was done using Chi-square test (Table 3). True Positive (TP) cases are 52, False Negative (FN) case is 01, True Negative (TN) cases 70 and no False Positive (FP) cases, $p=0.000$. Highly significant $(p \leq 0.001)$.

In Intraoperative Scrape Cytology (IOSC) the sensitivity was found $98.11 \%$, specificity $100 \%$, PPV 100\%, NPV 98.59\% and accuracy was $99.19 \%$.

Table 1 : Age distribution among the cases $(n=123)$

\begin{tabular}{lcc} 
Age in Groups & Frequency & Percentage (\%) \\
$\leq 20$ Years & 36 & 29.3 \\
$21-30$ Years & 39 & 31.7 \\
$31-40$ Years & 18 & 14.6 \\
$41-50$ Years & 16 & 13.0 \\
$51-60$ Years & 12 & 9.8 \\
$>60$ Years & 02 & 1.6 \\
Total & 123 & 100.0 \\
\hline
\end{tabular}

Mean- 31.41, SD- 14.31, Median- 26.00, Range- 12-65 years

Table 2 : Socio-demographic variables among the cases $(\mathrm{n}=123)$ Socio-demographic Variables Frequency Percentage (\%)

\begin{tabular}{llrl} 
Marital Status & Married & 89 & 72.4 \\
Socio-economic Status & Unmarried & 34 & 27.6 \\
& Poor* & 29 & 23.6 \\
& Average** & 84 & 68.3 \\
Occupation & Affluent*** & 10 & 08.1 \\
& House Wife & 74 & 60.2 \\
& Student & 22 & 17.9 \\
Family History of & Service Holder & 15 & 12.2 \\
Breast Lump & Garments Worker & 12 & 09.7 \\
Contraceptive & Yes & 14 & 11.4 \\
History & No & 109 & 88.6 \\
& Yes & 54 & 60.7 \\
\hline
\end{tabular}

* Poor class:-Family income Tk. 5000 or below per month **Average class:-Family income between Tk. 5000-15000 per month $* * *$ Affluent class:-Family income above Tk. 15000 per month
Table 3 : Association between IOSC \& histopathology (With $\chi^{2}$ test significance)

\begin{tabular}{lcccl}
$\begin{array}{l}\text { Intra-Operative } \\
\text { Scrape Cytology } \\
\text { (IOSC) }\end{array}$ & $\begin{array}{l}\text { Histopathology } \\
\text { Benign } \\
\text { Lesion }\end{array}$ & $\begin{array}{l}\text { Malignant } \\
\text { Lesion }\end{array}$ & $\begin{array}{l}\chi^{2} \text { test } \\
\text { Total }\end{array}$ & Significance \\
$\begin{array}{l}\text { Benign } \\
\text { Lesion }\end{array}$ & 70 & 01 & 71 & $\begin{array}{l}\chi^{2}=118.980 \\
\mathrm{p}=0.000\end{array}$ \\
Malignant Lesion & 00 & 52 & 52 & Highly \\
Total & 70 & 53 & 123 & Significant \\
\hline
\end{tabular}

Sensitivity-98.11 \%, Specificity-100.00 \%, PPV-100.00 \%, NPV-98.59\%, Percentage of False Negative-1.89\%, Percentage of False Positive- 0.00 \%, Diagnostic Accuracy- 99.19\%.

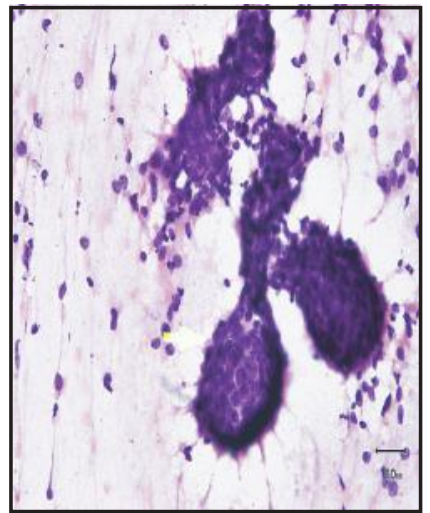

Figure 1 : Fibroadenoma (IOSC Smear) (Pap stain) 400X

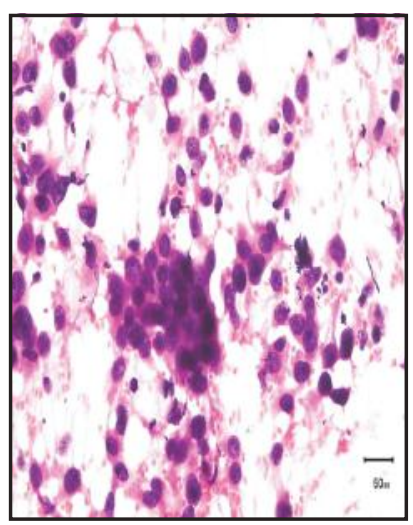

Figure 3 : Duct cell carcinoma (IOSC Smear) (Pap stain) 400X

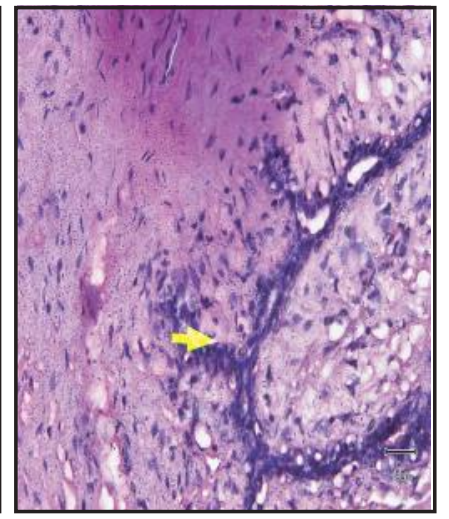

Figure 2 : Fibroadenoma

(Histopathology) (H \& E stain) 400X

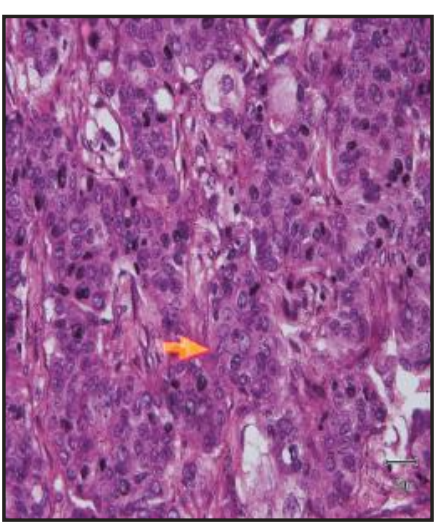

Figure 4 : Invasive Duct cell carcinoma (Histopathology) (H \&E stain) 400X

\section{DISCUSSION}

The age range of 123 patients was 12 to 65 years with maximum number of patients were in 21-30 years group, 39 (31.7\%). Rahman and Islam in their study showed highest number of patients $(38.13 \%)$ were in 21-30 years age group which is similar to our study ${ }^{12}$. Study done by Ramraje et $\mathrm{al}^{13}$. patient's age ranged from 12 to 70 years, majority of cases were between 21 to 40 years and 41 to 60 years respectively. 
Hiregoudar et al also showed age ranged from 13 to 65 years with most common benign and malignant lesions were 21 to 30 years and 31 to 50 years respectively which was consistent with our study ${ }^{6}$. In this study, among 123 cases, 89 (72.4\%) cases were married and $34(27.6 \%)$ cases were unmarried women. This is probably due to more married women presented to the out-patient department than unmarried ones. Though not directly related to this study, these figures may indicate the relative reluctance of young unmarried women to present to the out-patient department for a breast examination ${ }^{14}$. Present study revealed that, 14 (11.4\%) had family history of breast lump and $109(88.6 \%)$ had no family history. Among 14 cases with family history of breast lump, $3(21.3 \%)$ cases had family history of breast cancer. Tazzite et al showed $18.4 \%$ cases having family history of breast cancer which is nearer to our study $^{15}$.

Intraoperative scrape smears collected from 123 cases, reveal $71(57.7 \%)$ benign lesions and 52 (42.3\%) malignant lesions. On histological basis, among 53 malignant cases, 52 cases were diagnosed correctly by IOSC and 1 was diagnosed as benign, granulomatous mastitis (False negative) which subsequently confirmed histopathologically as lobular carcinoma. This may be due to similarity of monomorphic lobular carcinoma cells with chronic inflammatory cells and also due to resemblance of stromal cells to that of epithelioid cells. In a study we found that, Infiltrating Lobular Carcinoma (ILC) was missed for mastitis. This was explained as the inflammatory cells align themselves in the form of Indian files fashion and showed features typical of ILC. However, surgical and macroscopical examination findings were not conclusive for malignancy and the diagnosis on intraoperative cytology was that of mastitis ${ }^{16}$. There were no false positive cases in all scrape smears; similar finding was seen by Hiregoudar et al and Khudier et al ${ }^{16,17}$. This is probably because of the clear morphological features, adequate samples or results enhanced by using intraoperative cytology coupled with gross examination of surgical specimens ${ }^{17}$. All 70 histological benign cases were correctly diagnosed by IOSC.

Statistical analysis of the study cases was done considering the IOSC as screening test and histopathology as gold standard. In Intraoperative Scrape Cytology (IOSC) the sensitivity was found $98.11 \%$, specificity $100.00 \%$, PPV $100.00 \%$, NPV $98.59 \%$ and accuracy was $99.19 \%$. Akhter et al showed that sensitivity, specificity, PPV, NPV and accuracy for IOSC were remained $100 \%{ }^{1}$. Issam et al showed sensitivity, specificity and accuracy for IOSC were 95.8\%, 100\%, 96.8\% respectively ${ }^{7}$. Bukhari et al showed sensitivity, specificity, accuracy, PPV, NPV, for IOSC were $91.30 \%, 100 \%, 95 \%, 100 \%, 89 \%$, respectively ${ }^{18}$. Hiregoudar et al showed that sensitivity, specificity, PPV, NPV and accuracy for IOSC were 95.24\%, $100 \%, 100 \%, 95 \%, 97.5 \%$ respectively $^{6}$.
However, different studies have compared diagnostic efficacy of intraoperative scrape cytology with that of frozen section. Issam et al showed sensitivity, specificity and accuracy for IOSC were $95.8 \%, 100 \%, 96.8 \%$ respectively and for FS it were $91.7 \%, 100 \%$ and $90.3 \%$ respectively ${ }^{7}$. Bolkainy et al reported diagnostic accuracy of FS higher than IOSC and approved the relatively valid use of IOSC as an acceptable alternative in hospital with limited technical, financial and human supplies with available experienced cytopathologist ${ }^{19}$. In Bangladesh, breast lump is a common clinical problem, mostly in female. For proper surgical management and to achieve good prognosis, intraoperative scrape cytology will be very helpful. Most of the hospitals of Bangladesh including Chittagong Medical College Hospital are lacking facilities of frozen section. So intra-operative scrape cytology technique may fulfill the necessity of frozen section as it can be easily performed in many centers even in peripheral areas of this country.

Intraoperative scrape smears like frozen sections help in ontable diagnosis, with regard to the nature of tumours. This is of paramount importance wherein the FNAC is inconclusive or suspicious. Intraoperative scrape smears help in taking proper decisions with prior counseling of the patients, so that a repeat surgery is avoided. Intraoperative scrape smears are simple, accurate, rapid and cost effective diagnostic tool for intraoperative evaluation of breast tumours. The sensitivity and specificity support their utility intra-operatively wherein facilities for frozen sections are not available. In exact categorization of benign and malignant lesions of the breast, highest rate of diagnostic accuracy will be achieved when FNAC is combined with intraoperative cytology.

\section{CONCLUSIONS}

Intraoperative Scrape Cytology (IOSC) is a simple, accurate, rapid and cost-effective diagnostic tool, not requiring specific instruments in contrast to frozen section, can be used peroperatively for both diagnosis and management of breast lump.

\section{DISCLOSURE}

All the authors declared no competing interest. 


\section{REFERENCES}

1. Akhtar ZM, Qureshi SA, Aziz N, Niazi S, Qureshi SS, Bukhari MH. Evaluation of accuracy of intraoperative imprint cytology for detection of breast lesions. ANAALS. 2010; 16(1) : 48-54.

2. Liew PL, Liu TJ, Hsieh MC, Lin HP, Lu CF, Yao MS et al. Rapid Staining and Immediate Interpretation of Fine Needle Aspiration Cytology for Palpable Breast Lesions: Diagnostic Accuracy Mammographic, Ultrasonographic and Histopathologic Correlations. Acta Cytol. 2011; 55:30-37.

3. Tiwari M. Role of fine needle aspiration cytology in diagnosis of breast lumps. Kathmandu Univ Med J. 2007; 5(18): 215-217.

4. Bhuiyan MNI, Mimi SA, Rahman MZ, Khan MAH. Role of Fine Needle Aspiration Cytology in the Diagnosis of Breast Lumps- Analysis of 70 cases. Jalalabad Med J. 2011; 8(1): 16-19.

5. Kerlikowske K., Smith-Bindman R., Ljung BM., Grady D. Evaluation of Abnormal mammography results and palpable Breast abnormalities. Annals of Int Med. 2003; 139(4): 274-284.

6. Hiregoudar AD, Ashok GS, Prakash MR, Basavaraj GV, Shrishail M C. Accuracy of intraoperative imprint smears in breast tumours: A Study of 40 cases with review of literature. Ind J Surg. 2006; 68(6) : 302-305.

7. Issam FM, Das DK. Role of Fine Needle Aspiration, Intraoperative Imprint Cytology and Frozen Sections in the Diagnosis of Breast Lumps and Thyroid Lesions. Med Principles Pract. 1999; 8:173-182.

8. Kolte SS, Satarker RN. Role of scrape Cytology in the intraoperative Diagnosis of tumor. J Cytol. 2010; 27(3) : 86-90

9. Eltabbakh GH, Trask CE. Scrape cytology for intraoperative Evaluation of Lymph Nodes in Gynecologic Cancer.Obstet Gynecol. 2000; 95(1): 67-71.

10. Shidham VB, Gupta D, Galindo M., Haber M, Grotkowski C, Edmonds P et al. Intraoperative scrape cytology: Comparison with frozen sections, using Receiver Operating Characteristic (ROC) curve. Diagn Cytopathol. 2000; 23: 134-139.

11. Rao S., Sadiya N., Joseph LD., Rajendiran S. Role of scrape cytology in ovarian neoplasms. J Cytol. 2009; 26(1): $26-29$.

12. Rahman MZ, Islam S. Fine Needle Aspiration of palpable breast lump: A study of 1778 cases. Surgery. 2013; 12: 001.

13. Ramraje SN, Bharambe BM, Tote VD. Imprint smear cytology and histopathology of breast lesions-a comparative evaluation with review of literature. Cibtech J of Bio-protocols. 2012; 1(2):22-27.

14. Khemka A., Chakrabarti N., Shah S., PatelV. Palpable Breast Lumps: Fine-Needle Aspiration Cytology versus Histopathology: A Correlation of Diagnostic Accuracy. The Internet J Surg. 2009; 18(1) : 1-40.

15. Tazzite A., Jouhadi H., Saiss K., Benider A., Nadifi S. Relationship between family history of breast cancer and clinicopathological features in moroccan patients. Ethiop J Health Sci. 2013 ; 23(2): 150-157.

16. Al-Rikabi AC, and Al-Sohaibani MO. Intraoperative Cytology and Frozen Sections of Breast Lesions: A Comparison from a Saudi Teaching Hospital. Bahrain Med. Bull. 1996; 18(1):1-5

17. Khudier HH, Hawramy TA, Abdul-Qadir GM. Role of imprint cytology in breast lesions. Iraqi J Med Sci. 2009; 7(4) : 61-66.

18. Bukhari MH, Akhtar ZM. Comparison of Accuracy of Diagnostic Modalities for Evaluation of Breast Cancer with Review of Literature. Diagn Cytopathol. 2009; 37(6): 416-424.

19. Bolkainy TMNE, Shabaan HAM, Abodeif WT, Bolkainy MNE, Tony A E. Intraoperative diagnosis of breast mass lesions:Comparison of the validity of touch smear preparation and frozen section techniques. J Egypt Nat. Cancer Inst. 2008; 20(1): 63-69. 